\title{
P03-018 - Diversity in presenting manifestations of AUTOINFL
}

\author{
S Boiu ${ }^{1 *}$, B Neven ${ }^{1,2}$, S Compeyrot-Lacassagne ${ }^{1}$, R Mouy ${ }^{1}$, C Wouters ${ }^{1,2}$, B Bader-Meunier ${ }^{1,2}$, M Gattorno ${ }^{3}$, \\ Eurofever $^{1}, \mathrm{P}$ Quartier ${ }^{1,2}$ \\ From 7th Congress of International Society of Systemic Auto-Inflammatory Diseases (ISSAID) \\ Lausanne, Switerland. 22-26 May 2013
}

\section{Introduction}

The autoinflammatory diseases (AID) include monogenic and polygenic disorders characterized by primary dysfunction of the innate immune system.

\section{Objectives}

To describe the clinical spectrum, genetic background and therapy in a cohort of AID patients followed in a reference Pediatric Rheumatology center.

\section{Methods}

Medical records of AID patients followed between May 2007 and November 2010 and entered in the Eurofever Registry were studied.

\section{Results}

Fifty six patients were included: 17 Cryopyrin-Associated Periodic Syndromes (CAPS), 4 TNF-Receptor-Associated Periodic fever Syndrome (TRAPS), 5 Hyperimmunoglobulinaemia D with periodic fever Syndrome (HIDS), 18 Familial Mediterranean Fever (FMF), 6 Chronic Recurrent Multifocal Osteomyelitis (CRMO), 2 Synovitis, Acne, Pustulosis, Hyperostosis, Osteitis (SAPHO) syndrome and 4 Behçet's Disease (BD). The median followup was 2 years $(0-14)$. The male/female ratio was $20 / 36$. The median age was 2.5 years at disease onset and 4 at diagnosis. Family history was positive in $34 \%$ of patients. Clinical manifestations included fever (79\%), musculoskeletal (77\%), gastrointestinal (63\%), mucocutaneous (61\%), neurological (41\%), ocular (34\%), cardiorespiratory (13\%), and genitourinary (2\%) findings, lymphadenopathy with/ or hepatosplenomegaly (16\%) and growth impairment (25\%). Complications/sequelae developed in $45 \%$ of

'Pediatric Immunology, Hematology and Rheumatology Unit, Necker-Enfants Malades Hospital, Assistance Publique Hôpitaux de Paris, Paris, France Full list of author information is available at the end of the article patients. Six patients presented with unusual manifestations: neonatal peritonitis (1 CAPS), pancreatitis (1 TRAPS), acute glomerulonephritis (1 FMF), complicated Henoch -Schönlein purpura (1 FMF), peritoneal adhesions with intestinal occlusion (1 FMF), periorbital pain (1 CRMO) and cerebral thrombosis (1 BD). AID was associated with other diseases in 2 patients (FMF/ Henoch-Schönlein purpura and CRMO/enthesitis-related arthritis). One mutant allele was found in 16/17 CAPS, 4/4 TRAPS and 4/18 FMF patients. Two mutant alleles were present in 5/5 HIDS and 11/18 FMF patients. The most used therapeutic agents were biologics (54\%) (Anakinra, Canakinumab, Etanercept, Adalimumab), NSAIDs (48\%), colchicine (45\%) and corticosteroids (29\%). Anti-interleukin-1 therapy and colchicine proved efficacy in CAPS and FMF patients, respectively. In addition, favorable responses demonstrated anti-interleukin-1 therapy in TRAPS, HIDS and colchicine-resistant FMF patients, as well as Etanercept in TRAPS, HIDS and CRMO patients non-responsive to NSAIDs. $57 \%$ and $41 \%$ of patients were in complete and partial remission, respectively, at last visit.

\section{Conclusion}

AID in children are associated with a broad spectrum of manifestations. Early diagnosis and referral are essential as efficient therapy can be proposed in most cases.

\section{Competing interests}

None Declared.

\section{Authors' details \\ 'Pediatric Immunology, Hematology and Rheumatology Unit, Necker-Enfants Malades Hospital, Assistance Publique Hôpitaux de Paris, Paris, France. ²Paris- Descartes University and IMAGINE Institute, Paris, France. ${ }^{3}$ Departement of Pediatric Rheumatology, Gaslini Institute, Genoa, Italy.}

Published: 8 November 2013 
doi:10.1186/1546-0096-11-S1-A216

Cite this article as: Boiu et al:: P03-018 - Diversity in presenting

manifestations of AUTOINFL. Pediatric Rheumatology 2013

11(Suppl 1):A216.

Submit your next manuscript to BioMed Central and take full advantage of:

- Convenient online submission

- Thorough peer review

- No space constraints or color figure charges

- Immediate publication on acceptance

- Inclusion in PubMed, CAS, Scopus and Google Scholar

- Research which is freely available for redistribution 